\title{
Relationship Between Geometry and Ventricular Filling Pressures in Non-Diabetic Hypertensive Patients
}

\author{
Alejandro Suarez ${ }^{1,2}$ \\ ${ }^{1}$ Medicine Faculty, Catholic University, Guayaquil, Ecuador \\ ${ }^{2}$ Nahin Isaias Foundation, Guayaquil, Ecuador
}

Email address:

jonassuarezrobalino@hotmail.com

To cite this article:

Alejandro Suarez. Relationship Between Geometry and Ventricular Filling Pressures in Non-Diabetic Hypertensive Patients. Cardiology and Cardiovascular Research. Vol. 5, No. 3, 2021, pp. 135-140. doi: 10.11648/j.ccr.20210503.12

Received: May 24, 2021; Accepted: June 16, 2021; Published: July 9, 2021

\begin{abstract}
Hypertension and obesity make changes in the heart that are known as remodeling and diastolic dysfunction. These changes are the beginning of a later sistolic heart failure. Objectives Searching for the relation between geometry and ventricular function in hypertensive non diabetic and obese patients. 68 women and 20 men were evaluated by dopplerechocardiography. All patients had a normal ejection fraction. Results Ventricular geometry was altered in $53.4 \%$ of the subjects and diastolic function in $73.8 \%$ respectively. As body weight increased the ventricular mass, relative wall thickness, left atrial dimension and end diastolic volumes increased too. Overweight and obesity were found in $62.5 \%$ of the sample. A concentric left ventricular hypertrophy was present in $27.2 \%$ of the patients. An excentric left ventricular hypertrophy was found in $14.7 \%$ of them and $46.6 \%$ had a normal geometry. Eyection fraction values were lesser in the group with bigger ventricular mass and altered filling patterns. $\mathrm{P}=0.05,0.1$. Conclusion Arterial hypertension and obesity are risk factors for the development of cardiac abnormalities that lower systolic cardiac function in case of hypertrophy and dilatation are not resolved.
\end{abstract}

Keywords: Relative Wall Thickness, Left Ventricular Hypertrophy, Obesity, End Diastolic Volumes

\section{Introduction}

In hypertensive patients, left ventricular hypertrophy is common. Grossman in 1975 pointed out that ventricular hypertrophy in response to overload pressure was initially produced to normalize parietal stress of ventricle [1].

There is a stretch induced by high arterial pressure on the wall of the vessel and on the ventricular wall that leads to the generation of hypertrophy through angiotensin II and endotelin I and by the activation of the extracellular kinase protein regulated by signal. [2].

This ventricular hypertrophy of hypertensive origin is associated with high mortality and an increased risk for developing myocardial infarction, stroke, and heart failure. [3].

In line with this hypertrophy there is a remodeling that is defined as interstitial, cellular, molecular and genetic changes that alter the shape, volume and function of the heart.

These changes involve myocytes, fibroblasts, colagen, and intramyocardic vessels. As a result, cardiac performance deteriorates. This remodeling can be evaluated by the measurement of cardiac dimensions and shape, the measurement of the ventricular mass, the relative parietal thickness, the ejection fraction, and the end volumes of sistole and diastole. [4].

The left ventricular mass is defined as increased when it exceeds 200 grams, being the normal maximum for the ventricular mass index $125 \mathrm{~g} / \mathrm{m}^{2}$. [5].

The ventricular mass expressed in grams can be broken down for each individual using the left ventricular mass index (LVMI) obtained from dividing the ventricular mass for the body surface area. A study of 280 hypertensive followed by 10 years found that those with an LVMI greater than $125 \mathrm{~g} / \mathrm{m}^{2}$ had twice as many cardiovascular events $(26 \%$ vs $12 \%)$ and higher cardiovascular mortality ( $14 \%$ vs $1 \%)$ than those with a smaller LVMI..

Relative parietal thickness (RPT) evaluates the relationship between the parietal thickness and the diameter of the ventricular cavity by formulating the rear wall diameter in 
squared diastole divided by the ventricular diastolic diameter whose normal values are between 0.42 and 0.45 . Combining the 2 measurements (LVMI and RPT) ventricular geometry can be classified in hypertensive patients. [6].

But in cardiac changes caused by arterial hypertension, not only ventricular geometry (remodeled) is altered but also the diastolic function of the left ventricle causing delayed and incomplete relaxation and increased wall stiffness all resulting in increased filling pressures of the ventricle, pulmonary congestion and dyspnea. [7].

To diagnose diastolic dysfunction [DD] it is considered the existence of symptoms and signs of cardiac insuffiency (CI), that a normal ejection ventricular fraction is found, and echocardigraphy data of ventricular diastolic dysfunction such as elongation of the ventricular relaxation period (IVRT), shortening of rapid ventricular filling, reduction of the distensibility of the ventricle, and increased lateral stiffness.

In this research we consider a normal ejection fraction (EF) value of $50 \%$ or more. Some authors will also consider for the diagnosis of DD an end-of-diastole volume index (EDV) less than $102 \mathrm{ml} / \mathrm{m}^{2}$. [8]. This study considers an end-of-diastole volume value less than $97 \mathrm{ml} / \mathrm{m}^{2}$ which together with an EF of $50 \%$ or more are the criteria of the Echocardiography Association of the European Society of Cardiology. [9].

As for IVRT a value greater than $100 \mathrm{~ms}$ is considered pathological in this research, the same is considered to be a slowing time (TDESC) of rapid filling less than $150 \mathrm{~ms}$ or greater than 250. [10]. It is important to study the alterations that arterial hypertension causes in the heart filling function. The increased postload status affects ventricular relaxation and the greater this is, the greater the delay in relaxation.

It must be remembered that the same neurohormone that originates ventricular htpertrophy is involved in the production of increased ventricular stiffness.

Ventricular hypertrophy originates in many hypertensive patients as a result of pressure overload. Well, this hypertrophy disturbs the displacement of calcium by delaying ventricular relaxation. In this regard, it should be remembered that in a normal diastole calcium levels are low due to the displacement of the ion from the cytoplasm to the sarcoplasmic reticulum. [11].

When relaxation is abnormal, the time that measures it (IVRT) is prolonged and a slower fall of the pressure is observed inside the left ventricle thus decreasing the rapid fill rate, a speed that is measured by the height of wave E. It should be remembered that ventricular rapid filling occupies one third of the diastole and is equivalent to two-thirds of the end-of-diastole volume (EDV).

As for the ventricular distensibility that Brutsaert says corresponds to the slow filling and atrial counter-action phases this is important after ventricular relaxation has been completed and the pressures between the atrium and ventricle have been balanced, causing the rapid filling to decrease or decelerate.

On distensibility influences energy metabolism and we see that the hypoxia seen in myocardic ischemia decreases it by increasing ventricular stiffness. [12]. This rapid filling deceleration is measured by the deceleration time.

The end-of-diastole volume is the volume present at the time of ventricular contraction and is composed of the volume left in the ventricle after the ejection of it plus the venous return. It's equivalent to preloading. Under normal conditions it ranges from 120 to $140 \mathrm{ml}$. [13]

In diastolic dysfunction when decreasing filling decreases ventricular EDV.

Another parameter measured in diastolic dysfunction is the left atrium. In a normal diastolic function with a negative left ventricular pressure to the atmospheric at the start of rapid filling, the left atrium contributes 15 to $25 \%$ to the filling of the telediastole as long as the sinus rhythm is preserved.

When ventricular relaxation is altered the pressure inside the left ventricle increases thus decreasing the volume of early filling. In these circumstances, the pressure on the left atrium increases and the left atrium is contracted more strongly in order to maintain an optimal end-of-diastole pressure (EDP) that ensures a normal ejection volume.

As diastolic dysfunction worsens over time, it decreases atrial contractility and decreases its contribution to ventricular filling. Result: increasing the end-of-sistole volume due to a decrease in sistolic expenditure will increase the volume of end of diastole. [14]

\section{Methodology}

Hypertensive patients were randomly selected, with no age limit. Patients in atrial fibrillation, chronic renal impairment, valvular disease, with cardiomyopathies, corpulmonary or congenital cardiopathies were excluded. Body mass index (BMI) between 25 and $29.9 \mathrm{~kg} / \mathrm{m}^{2}$, correspond to grade 1 obesity, BMI between 30 and 34.9, to grade 2 obesity, BMI between 35 and 39.9 to grade 3 obesity and when BMI was greater than $40 \mathrm{Kg} / \mathrm{m}^{2}$ corresponded to grade 4 obesity.

An abnormal blood pressure value is considered a systolic above $120 \mathrm{mmhg}$ and a diastolic above $80 \mathrm{mmhg}$. All patients had a doppler echocardiogram and measurements were made according to the recommendations of the American Society of Echocardiography.

The variables analyzed were ventricular ejection fraction, ventricular mass, relative parietal thickness, end-of-sistole and diastole volumes, left atrium size, systolic arterial pulmonary pressures (PSAP) and maximum E-wave speed of mitral filling and its relationship to atrial counter-action filling wave A.

\section{Results}

88 patients were included in this study, 68 women (77.2\%) 20 men $(22.7 \%)$ with an average age for women aged 68.3 and for men aged 57.5 all diagnosed with arterial hypertension. The age ranges of the sample were between 16 and 92 years old. $41(46.6 \%)$ patients were obese, $14(16 \%)$ were overweight, so $62.5 \%$ were outside the normal weight range. BMI ranged from 19.6 to $41.9 \mathrm{Kg} / \mathrm{m}^{2}$.

No diabetes mellitus was detected in any of them. The 
average blood glucose rate was $97.1 \mathrm{mg} / \mathrm{dL}$ (DE 0.9). In 29 patients $(32.9 \%)$ dyslipidemia was found. A complete blockage of the right branch of the His Bundle was found in the electrocardiogram in 2 patients $(2.2 \%), 4(4.5 \%)$ had a $1 \mathrm{st}$ degree A-V blockage, bi-fascicular blockage was found in 2 individuals $(2.2 \%)$, myocardial ischemia was detected in 6 subjects $(6.8 \%)$, and myocardial infarction in $2(2.2 \%)$.

Table 1. Sex, age and percentage of remodeling and diastolic dysfunction.

\begin{tabular}{llll}
\hline Women & \multicolumn{3}{l}{ Men } \\
\hline Number & $68(77.2 \%)$ & Number & $20(22.7 \%)$ \\
Age & $68.3 \times$ D.E 2.9 & Age & $57.5 \times$ D.E 19.2 \\
BMI & 31.7 & BMI & 33 \\
HAS & 68 & HAS & 20 \\
Vent. Remodeling & $34(50 \%)$ & Vent. Remodeling & $13(65 \%)$ \\
Diast. Dysfunction & $51(75 \%)$ & Diast. Dysfunction & $14(70 \%)$ \\
\hline
\end{tabular}

\section{Echocardiographyc Findings}

A normal ventricular geometry was found in 34 (50\%) of women, and in men in $7(35 \%)$. The rate of ventricular remodeling in women was $34(50 \%)$ and in men was of 13 $(65 \%)$. This indicates that in hypertensive patients the percentage of cardiac deformation is high.

Table 2. Distribution of Cardiac Remodeling

\begin{tabular}{llll}
\hline Women & \multicolumn{3}{l}{ Men } \\
\hline $\mathrm{N}$ & $34(50 \%)$ & $\mathrm{N}$ & $7(35 \%)$ \\
$\mathrm{HE}$ & $6(8.8 \%)$ & $\mathrm{HE}$ & $7(35 \%)$ \\
$\mathrm{HC}$ & $20(29.4 \%)$ & $\mathrm{HC}$ & $4(20 \%)$ \\
$\mathrm{RC}$ & $8(11.7 \%)$ & $\mathrm{RC}$ & $2(10 \%)$ \\
\hline
\end{tabular}

Table 4. Relation between weight, left ventricular mass, left atrium size and end diastolic volumes.

\begin{tabular}{|c|c|c|c|c|c|}
\hline Patients Number 48 & BMI & MASS (VMI) & RPT & LA & EDV \\
\hline Normal Weight & $23.0 \mathrm{DE} 1.2$ & $158.3 \mathrm{DE} 6.0$ & 0.40 DE 0.09 & $33.2 \mathrm{DE} 5.3$ & $45.9 \mathrm{DE} 4.5$ \\
\hline Overweight & $27.1 \mathrm{DE} 1.5$ & 139.8 DE 37.9 & 0.42 DE 0.05 & $29.0 \mathrm{DE} 4.5$ & 44.4 DE 0.56 \\
\hline Obesity Class 1 & $32.7 \mathrm{DE} 0.98$ & 219 DE 17.7 & 0.44 DE 0.02 & 36.2 DE 2.8 & $51.7 \mathrm{DE} 16.4$ \\
\hline Obesity Class 3 & $41.3 \mathrm{DE} 0.07$ & $222.7 \mathrm{DE} 48.4$ & $0.47 \mathrm{DE} 0.09$ & 46.1 DE 14.8 & 56.3 DE 30.8 \\
\hline
\end{tabular}

Regarding ventricular filling, it prevailed in both groups the abnormal filling pattern giving a total of 65 individuals $(73.8 \%)$ for the entire sample, confirming that the increase in postloading is a very important factor in the genesis of alterations in relaxation and ventricular compliance. Obviously other factors such as age and weight of respondents also play a role, recalling that $62.5 \%$ of patients had weight gain.

The filling disorder that was most found was that of prolonged relaxation with $72.7 \%$ of the entire population. The percentage of the pseudonormal pattern was small $(5 \%)$ and found only among men, but it must be clarified that there are no records of tissue doppler.

Table 5. Types of ventricular filling patterns.

\begin{tabular}{llll}
\hline $\mathrm{W}$ & N 17(25\%) & RP 51 (75\%) & SEUDON 0 \\
$\mathrm{M}$ & N 6 (30\%) & RP 13(65\%) & SEUDON 1 (5\%) \\
\hline
\end{tabular}

Ventricular hypertrophy was already said to disrupt the calcium cycle by altering Serca 2 a by slowing down relaxation. When we relate ventricular mass to filling patterns we find in
The percentage of abnormal geometry in the sample was $53.4 \%$. All patients had a normal ejection fraction or above $50 \%$, with an average for women of 66.7 and for men of $66.2 \%$. The size of the left atrium did not exceed the $40 \mathrm{~mm}$ normal range, being the average for women of 33.8 and for men of $38.7 \mathrm{~mm}$.

The values of the end-of-diastole volume were $47.1 \mathrm{ml}$ in the women's group and $69.7 \mathrm{ml}$ in the men's group, all values within the normal range.

Table 3. Echocardiography Dimensions.

\begin{tabular}{llll}
\hline Women & \multicolumn{3}{c}{ Men } \\
\hline EF & 66.7 - x D.E 1.5 & EF & 66.2 - x D.E 5.6 \\
LA & 33.8 - x D.E 1.7 & LA & 38.7 - x D.E 2.4 \\
\hline
\end{tabular}

Concentric ventricular hypertrophy that is the most associated cardiac remodeling with adverse cardiovascular events was found in 20 women $(29.4 \%)$, and in 4 patients $(20 \%)$ of the group of men. This indicates that a non-negligible number of hypertensive patients $(27.3 \%)$ is at risk of negative events such as arrhythmias or death of cardiovascular origin.

Excentric hypertrophy was found in 6 women $(8.8 \%) 7$ male patients (35\%). Total $14.8 \%$. As there was a significant percentage of out-of-the-ordinary weight patients, the relationship between the various degrees of overweight and obesity was found according to BMI with

echocardiography variables such as ventricular mass, relative parietal thickness, left atrium size and end-of-diastole volumes. The results are shown in Table 4. women with normal filling a mass of $147.2 \mathrm{~g}$ with an D.E of 58.8 compared to a mass greater than 205.6 with a D.E 14.4 in women with delayed filling.

In men the same thing happened with mass values of 200.6 $\mathrm{g}$ and D.E. of 46.7 in those which had normal filling vs a mass of 216 with a D.E. of 55.4 for those with prolonged filling. Interesting data was found when linking end-of-diastole volume values to ventricular filling values in the largest group of patients that was women's.

Although these EDV values were within the normal range throughout the sample, in the group of women with normal filling the EDV was $35.6 \mathrm{ml}$ instead in the delayed filling group was $52.1 \mathrm{ml}$ which demonstrates the effect of diminished compliance on pressure inside the ventricle. P-0.4. Table 6.

This data was not found in the group of men perhaps due to the smaller number of subjects.

This was verified when finding that EDV throughout the sample with relaxation delay was $59.5 \mathrm{ml}$ versus a value of 
$49.8 \mathrm{ml}$ in male patients with normal relaxation. Table 7.

Table 6. Relationship between ventricular filling and EDV.

\begin{tabular}{ll}
\hline WOMEN WITH R e $/ \mathrm{a}<1$ & ESV \\
0.716 - x D.E 0.04 & 52.1 - x D.E 4.6 \\
WOMEN WITH R e $/ \mathrm{a}>1$ & ESV \\
1.2 - x D.E 0.09 & 35.6 - x D.E 9.1 \\
\hline
\end{tabular}

Table 7. Relationship between EDV and ventricular filling.

\begin{tabular}{lll}
\hline Relationship e/a $<1$ & EDV & 59.5 \\
& D.E & 25.3 \\
Relationship e/a $>1$ & EDV & 49.8 \\
& D.E & 33.4 \\
\hline
\end{tabular}

Obviously all this influences the cardiac output $(\mathrm{CO})$ of the ventricle since increasing the end-of-sistole volume (ESV) as there is a slight decrease in systolic output would contribute to the increase in EDV. The percentage of atrial contractility also comes into play here.

We then compared the ejection fraction $(E F)$ in patients with normal filling patterns versus ejection fraction in patients with altered filling and found that in men with normal filling EF was $69.8 \%$ vs. an EF of $64.5 \%$ when they had prolonged relaxation. P-0.10-0.05. With women, the same thing happened those which had normal filling had an EF of $68.8 \%$ vs an EF of $66.6 \%$ when they had prolonged relaxation. P-0.15-0.10.

As in a normal ventricular filling pattern this occurs with low left atrial pressures, it was intended to seek the relationship between atrium size and the EDV. It was found that in women with a normal atrium size the EDV was $45.8 \mathrm{ml}$ while with a larger auricula but within normal this volume was 76.7 ml. P. 0.15-0.10.

In men something similar happened, with a normal left atrium the EDV was $61.2 \mathrm{ml}$ and increased to $106.5 \mathrm{ml}$ when the auricula was larger in size. Table 8.

Table 8. Relationship between Auricula size and EDV.

\begin{tabular}{llll}
\hline Women & ESV & Men & ESV \\
\hline NA -1 & $45.8-x$ DE 3.7 & NA - 1 & $61.2-$ x DE 19.5 \\
NA - 2 & $76.7-x$ DE 42.3 & NA - 2 & $106.5-$ x DE 55.4 \\
NA -1 & Normal Auricula & NA -2 & Auricula $>$ Size \\
\hline
\end{tabular}

We related the values of ventricular mass, end-of-synstole volume (ESV) and ejection fraction in the most numbered group that was that of women, comparing those that had normal values of ventricular mass with the group that had increased mass (hypertrophy).

In the group of women with normal mass the average ejection fraction (EF) was $67.4 \%$ and the end-of-systole volume (ESV) of $12.2 \mathrm{ml}$ against an EF of $65.6 \%$ and an ESV of $15.7 \mathrm{ml}$ in the group with ventricular mass above 200 gr. In the mass and ESV ratio the p-value was 0.05-0.02. Table 9

Table 9. Relation between ventricular mass, ejection fraction and ESV.

\begin{tabular}{llll}
\hline Women & MASS & EFVI & ESV \\
\hline NORMAL MASS & $145.8 \pm$ DE 2.4 & $67.4 \pm$ DE 1.9 & $12.2 \pm$ DE 0.8 \\
INCREASED MASS & $247.5 \pm$ DE 37.9 & $65.6 \pm$ DE 5.0 & $15.7 \pm$ DE 8.8 \\
\hline
\end{tabular}

\section{Discussion}

Ventricular hypertrophy (VH) is a morphological and functional adjustment mechanism in response to elevated blood pressure. It has been seen that this adaptation of the heart is heterogeneous and gives rise to the different geometric patterns of hypertrophy. In concentric $\mathrm{VH}$ the heart shape is elliptical, peripheric resistances are considered to be increased, instead in excentric $\mathrm{VH}(\mathrm{EVH})$ there is a spherical geometry and vascular resistances are diminished. [15]

In this study, the percentage of concentric ventricular hypertrophy $(\mathrm{CVH})$ was $27.3 \%$ and the percentage of excentric ventricular hypertrophy $(\mathrm{EVH})$ was $14.8 \%$ for a population of 88 patients. In LIFE study $25 \%$ had CVH and $45 \%$ had EVH. There were 964 patients evaluated. [10]

In our results, the small number of male patients (No. 20) may have influenced.

These different adaptation patterns could be due to various factors such as the state of periphery vascular resistances, plasma renin levels. A Schmeider study found that patients with diastolic blood pressure (DBP) less than $90 \mathrm{mmHg}$ had a higher cardiac output, decreased peripheral resistances (DPR), and with EVH in their geometry.

In contrast, patients with a DBP > $95 \mathrm{mmhg}$ had a normal cardiac output, increased vascular peripheral resistances and a pattern of concentric ventricular hypertrophy. [16] But these findings involve not only the arterial hypertension of respondents but also weight gain.

In our research, the number of patients with higher than normal weight was significant (62.5\% of patients).

Studies in ventricular remodeling in obese patients have shown increased heart weight, increased ventricular parietal thickness, increased left ventricular mass and a left atrium growth. Kasper in 409 non-obese subjects and 43 with obesity and heart failure observed a higher incidence of dilated myocardiopathy in obese than in non-obese people. [17]

In our research we observed that as the weight of patients increased, at the same time the ventricular mass, the relative parietal thickness, the size of the left atrium and the end-of diastole volumes increased, which is not fully explained by the existence of coexisting arterial hypertension. (Table 4). Excessive fat accumulation would increase blood volume, which in turn would increase cardiac output.

There would be an increase in preload that by La Place law would cause some hypertrophy and also delation of the chamber causing excentric ventricular hypertrophy so frequently found in obesity. This would lead to ventricular diastolic dysfunction and increased end diastolic volume as shown in our study

In the larger group (women) there was a higher percentage of concentric ventricular hypertrophy than excentric ventricular hypertrophy which could be explained by the increase in peripheral resistances and therefore in the postload caused by co-existing arterial hypertension. Some studies indicate that excentric ventricular hypertrophy is not unique to obesity and that concentric ventricular hypertrophy and concentric remodeling (CR) occur in a significant number of 
patients. $[18,19]$

As for ventricular filling an altered pattern was found in 65 individuals (73.8\%) which is consistent with studies indicating the presence of diastolic dysfunction in up to $70 \%$ of patients with 70 or more years. [20] In our study the average age of the largest group was 68.3.

The fact that left ventricular hypertrophy delays ventricular relaxation and therefore increases end diastolic volumes is demonstrated in our study by the fact that greater ventricular mass was found in women with ventricular filling delay. This delay in ventricular relaxation increases end diastolic volume (table 6) and this would result in greater contractile strength of the atria to ensure a better ventricular filling. Table 7.

As there is a growing end diastolic pressure in the evolution of the disease this will be reflected in the left atrium dimension that progressively will increase. This is demonstrated in Table 8 where a larger EDV is shown to correspond to a larger atrial size although within normal ranges.

We also see that ventricular hypertophy is associated with a progressive decrease in ejection fraction and an increase in end-of-sistole volume compared to patients without $\mathrm{LVH}$, and although in this work these values still fall within normal ranges however over time if ventricular hypertrophy is not controlled it will take them to levels already definitely abnormal of sistolic function. Table 9 .

Finally, in ventricular filling pattern disorder also influences the presence of obesity entity so commonly present in hypertensive patients and that affects diastolic function independently. The association between insulin resistance common in obesity - and prolongation of isovolumetric relaxation time has been demonstrated. [21]

In addition to obesity there is an increase in preload which would mask the real incidence of pseudonormal filling pattern if only the pulsed doppler of mitral filling is used as in this case. Therefore, the recommendation is to also use tissue doppler that allows the diagnosis of pseudonormalized pattern even among varieties of abnormal filling pattern as when prolonged relaxation is included. [22]

\section{Conclusions}

Arterial hypertension is one of the main causes of cardiac remodeling and alters both ventricular geometry and diastolic filling function. This indicates that the factors that cause the increase in ventricular mass in hypertension are the same as those that increase ventricular stiffness that leads to diastolic dysfunction.

In this research we see how arterial hypertension associated with another very common risk factor such as obesity together produce ventricular hypertrophy, increase parietal thickness, disrupt ventricle filling, increase diastolic pressures of the chamber and eventually affect the progressive decrease in systolic output and ejection fraction.

This could mean the progression of diastolic dysfunction with initial disorders in ventricular relaxation and then progress to future stages of systolic dysfunction.

We see how the greater the degree of obesity is observed the greater is the deterioration of these variables. This is important in subjects carrying metabolic syndrome where arterial hypertension is one of the key points for diagnosis along with the presence of obesity or overweight plus hypertriglyceridemia or fasting blood glucose disturbance.

New technologies in cardiology such as 3D speckle tracking imagine are providing valious information about left ventricular function. This is important because heart failure with preserved ejection fraction still have diagnose problems at this moment [23].

The disposition of fibers in the cardiac structure is complex and it has been proved that contraction of longitudinally or circumferentially myocytes produce a range of ejection fraction of $15 \%$ and $28 \%$ respectively, and that fibers with a 60 degree angle from the horizontal plane give an additionally ejection fraction of more than $60 \%$.

So there is a relationship between left ventricular geometry, strain and mortality in heart failure patients.

It seems that left ventricular global longitudinal strain is more sensitive than the E/e'ratio to detect left ventricular dysfunction.

Therefore in the control of hypertensive patients we must not only take into account achieving optimal arterial tension figures but also we must monitor the status and evolution of the systolic and diastolic functions of the heart. As a limitation in our research it is noted that we do not have tissue doppler data such as the E/e' relationship that allow us to locate the real prevalence of pseudonormal filling or the congestive state of patients.

\section{References}

[1] Katz AM. The cardiomyopathy of overload: an unnatural growth response. Eur Heart J 1995; 16 (suppl 0): 0-110-14.

[2] Yamazaki T, Komuro I, Yasaki Y: Role of the reninangiotensin system in cardiac hypertrophy. Am J Cardiol 1999; 83: $53 \mathrm{H}-57 \mathrm{H}$.

[3] Levy D, Garrison RJ, Savage DD, Kannel WB, Castelli WP: Prognostic implications of echocardiographically- determined left ventricular mass in the Framingham Heart Study. N Engl J Med 1990; 322: 1561-1566.

[4] Cohn J, Ferrari R. Cardiac remodeling concepts and clinical implications: A consensus panel from an International Forum on cardiac remodeling. Journal of American College of Cardiology 35 (3): 569-582, Ref: 132, 2000.

[5] Pearson AC, Pasierski T, and Labovitz AJ: Left ventricular hypertrophy: Diagnosis, prognosis and management. Am Heart J 1991; 121: 148-157.

[6] Koren MJ, Devereux RB, Casale PN, Savage DD, Laragh JH. Relation of left ventricular mass and geometry to morbidity and mortality in uncomplicated essential hypertension. Ann Intern Med 1991; 114: 345- 352.

[7] Mac Carthy PA, Shah AM: Impaired endothelium- dependent regulation of ventricular relaxation in pressure- overload cardiac hypertrophy. Circulation 2000; 101: 1854-60. 
[8] E. Molinero de Miguel, Sagastagoitia Gorostiza JD. Diagnostico y tratamiento de la disfuncion ventricular diastolica. Servicio de Cardiologia, Hospital de Bazurto, Departamento de Medicina, Universidad del Pais Vasco (UPVEHU), Bilbao.

[9] Paulus WJ, Tschope C, Sanderson JE, Rusconi G, Flachskampf FA, Rademakers FE et al. How to diagnose diastolic heart failure: a consensus statement on the diagnosis of heart failure with normal left ventricular eyection fraction by the Heart Failure and Echocardiography Associations of the European Society of Cardiology. Eur Heart J 2007; 28: 2539-50.

[10] Wachtell K, Smith G, Gerdts E, Dahlof B, Nieminen MS, Papademetriou V, Bella JN, Ibsen H, Rokkedal J, Devereux RB. Left ventricular filling patterns in patients with Systemic Hypertension and Left Ventricular Hypertrophy (The LIFE study). Am J Cardiol 2000; 85: 466-472.

[11] Edvanseut T, Rosen BD, Pan L et al. Regional diastolic dysfunction in individual with LVH measured by magnetic resonance imaging. The multiethnic study of atherosclerosis (MESA). Am Heart J 2006; 151: 109-14.

[12] Zile MR, Brutsaert DL. New concepts in diastolic dysfunction and diastolic heart failure, Part 1. Diagnosis, prognosis and measurements of diastolic function. Circulation 2002; 105: 1387-93.

[13] Jalil MJ. Fisiologia cardiovascular, Escuela de Medicina, Curso MED 301A integrado de Clinicas II. Capitulo Fisiopatologia Cardiovascular. Sept 2012.

[14] Tsang TS, Barnes ME, Gersh BJ, Bailey KR, Jeward JB. Left atrial volume as a morphophysiologic expression of left ventricular diastolic dysfunction and relation to cardiovascular risk burden. Am J Cardiol 2002; 90: 1284-9.

[15] Davila DF, Donis JH, Odreman R, Gonzalez M, Landaeta A. Adaptacion morfologica del corazon a la hipertension arterial esencial. Fisiopatologia e implicaciones terapeuticas. Avances Cardiol 2009, 29 (2). 144-153.

[16] Schmeider RE, Schobel HP, Messerli FH. Central blood volume A determinant of early cardiac adaptation in arterial hypertension. J Am Coll. Cardiol. 1995, 26. 1692-1698.

[17] Kasper EK, Hruban RH, Baughman KL. Cardiomyopathy of obesity. A clinical pathologic evaluation of 43 obese patients with heart failure. Am J Cardiol. 1992; 70: 921-4.

[18] Woodwiss AJ, Libhaber CD, Majane OH, Libhaber E, Maseko M, Norton GR. Obesity promotes left ventricular concentric rather than eccentric remodeling and hypertrophy independent of blood pressure. Am J Hypertension. 2009; 21: 1144-51.

[19] Martin A Alpert y Eric J Chan. Morfologia ventricular izquierda y función diastólica en la obesidad grave: perspectivas actuales. Rev Esp Cardiol. 2012; 65 (1): 1-3.

[20] Paul Leal Gaxiola. Disfuncion diastólica: diagnostico y tratamiento. Revista Mexicana de Anestesiologia, Medicina Critica. Vol 31 Supl 1, Abril- Junio 2008, PP S144- S145.

[21] Galderisi M, Paolisso G, Tagliamonte MR, Alfieri A, Petrocelli A, De Divitijs M, Varricchio M, De Divitijs O. Is insulin action a determinant of left ventricular relaxation in uncomplicated essential hypertension? J Hypertens 1997; 15: 745-50.

[22] Iglesias Garriza I, Rodriguez Garcia MA, Delgado Fernandez S, Garrote Coloma C, Sastre Ibarretxea M, Corral Fernandez F. Doppler tisular del anillo mitral en pacientes con disfuncion sistolica ventricular izquierda. Analisis de la funcion diastolica. Revista Espanola de Cardiologia. Vol 53. Num 9. Paginas 1195-1200, Septiembre 2000.

[23] Dadic M, Pieske-Kraigher E, Cuspidi C, Genger M, Morris D A, Zhang K, Walther N A, Pieske B. Left ventricular strain and twisting in heart failure with preserve dejection fraction: an updated review. Heart Fail Rev (2017) 22: 371-379. 